\title{
EXPERIMENTAL RESEARCH IN LIQUID BATCHER MIXER
}

\author{
Aleksandr Kolesnikov, Nataliia Vodolazskaya, Alexan Minasyan, Konstantin Kazakov \\ Belgorod State Agricultural University named after V. Gorin, Russia \\ a.c.kolesnikov@mail.ru,vnv26@bk.ru, alikmun@yandex.ru, kazakovbelgorod@mail.ru
}

\begin{abstract}
The main operations of the process of producing multicomponent mixtures are dosing and mixing operations. The technology of vegetable protein production from sugar beet processing wastes involves the process of dosing and mixing organic acid solution with squeezed juice. The optimal selection of process equipment has an impact on the quality of the obtained product. These processes can be carried out using a liquid batcher mixer. The analysis of the design features of the existing batcher mixers showed their main disadvantages. There are the nonuniformity in the distribution of the additional liquid in the main liquid flow, the additional energy costs for driving the mixing element and the low degree of homogeneity of the finished mixture. An experimental plant for conducting researches of a batcher mixer has been developed. Analysis of the functioning of the used equipment was carried out to determine the main parameters of the liquid dosing and mixing processes. The design diagram of measuring instruments arrangement at the experimental assembly is presented. The purpose of the research in the liquid batcher mixer was to determine the dependencies of qualitative indicators of the obtained mixture on the design parameters. Functions of uniformity of distribution of solution of organic acids in juice on the design parameters of the batcher mixer are shown. Dependencies of coagulation time and the amount of the obtained protein on the content of organic acid solution are presented. Experimental researches made it possible to substantiate the optimal design and technological parameters of the batcher mixer.
\end{abstract}

Keywords: juice, beet pulp, vegetable protein, a batcher mixer, organic acids.

\section{Introduction}

At the present stage of the development of the agro-industrial complex, questions of ensuring the quality of agricultural products are of particular relevance, both in state and regional significance [1]. These issues cannot be resolved without a timely production upgrade, which is a complex, partial or complete upgrade of the plant's systems and equipment [2;3]. Modernization as a fundamental problem consists of narrower problems, including not only the development of new types of industrial equipment [4], but also the restoration of parts during repair work [5], the improvement of existing equipment [6], and without damaging the environment [7].

With regard to agricultural processing enterprises, their main task is to obtain food for humans and provide farm animals with feed. Dosing and mixing operations of components are often included in the process line in the production of multicomponent animal feeds [8; 9]. For example, in the production of vegetable protein from beet pulp, squeezed juice is mixed with a solution of organic acids [10]. Therefore, the main parameters characterizing the working process of the liquid batcher mixer are the uniformity of application and the uniformity of distribution of the organic acid solution in the juice. The analysis of the design features of the mixers shows that their disadvantages include: non-uniformity of the distribution of the additional liquid in the main liquid stream [11], additional energy costs for the drive of the mixing element [12] and a low degree of homogeneity of the finished mixture [13].

Since the quality of the finished product depends on the correct selection of the process equipment used in production [14], the development of the most optimal design of the batcher mixer is an important task that needs to be solved. The analysis of liquid mixer designs shows that the most promising are inline mixers with rotating mixing elements, the study of which is devoted to this work.

\section{Materials and methods}

In previous studies of the authors [15], it was theoretically proved that the main indicators listed above depend on:

- density of the organic acid solution, which varies depending on the number of components included therein;

- speed of the main stream of juice;

- reactive force resulting from the flow of organic acid solution from the holes of the mixing element;

- geometric parameters of exit holes of the mixing element. 
Based on this, the task of the experimental studies of the liquid batcher mixer included: checking theoretical provisions, identifying a number of physical values and coefficient values and substantiating the optimal parameters and operating modes of the proposed mixer dispenser.

In accordance with the task, the work was carried out to the following program:

- identification of rational geometry of exit holes of the mixing element;

- determination of the dependence of the specific resistance to mixing of juice and solution of organic acids on the rotation frequency of the mixing element, reactive force of flow of solution of organic acids and the density of mixed liquids;

- determination of the nature of application and distribution of the solution of organic acids in the juice;

- laboratory studies to optimize the main parameters of the dosing mixer.

The experimental research program provided for: checking the validity of theoretical research; experimental determination of optimal parameters of a liquid mixer dispenser; refinement of some theoretical dependencies using physical quantities and coefficients. The experimental research was preceded by the analysis of scientific works, for example, using APM WinMachine CAE [16], methods of mathematical modeling [17], as well as the theoretical analysis and synthesis of the processes and phenomena studied, the collection and processing of a priori experiment data, the construction of an experimental research plan and the solution of technical, biological and organizational measures for its implementation.

Experimental studies were carried out in accordance with a number of generally accepted methods for determining the qualitative, biological, energy parameters of machines and equipment and the method of mathematical processing of data. The method of mathematical processing of experimental data has solved the following issues:

- select rational measuring equipment and justify repetition of measurements;

- analyze the errors of the measured geometric, kinematic, dynamic and other parameters in order to eliminate systematic errors;

- present the obtained experimental data in a well-behaved tabular or graphical form;

- establish the extent of the relationship between phenomena;

- determine the optimal solution of the given task.

Processing of the experimental data and analyses of dependencies were carried out using statistical methods of processing using a computer. The method of planning multifactor experiments was used when studying the operation of the liquid batcher mixer.

It was possible to reduce the volume of experimental studies, evaluate the reliability of their results and build mathematical models of processes in order to optimize them using this method.

\section{Results and discussion}

An experimental plant was manufactured for the research (Fig. 1).

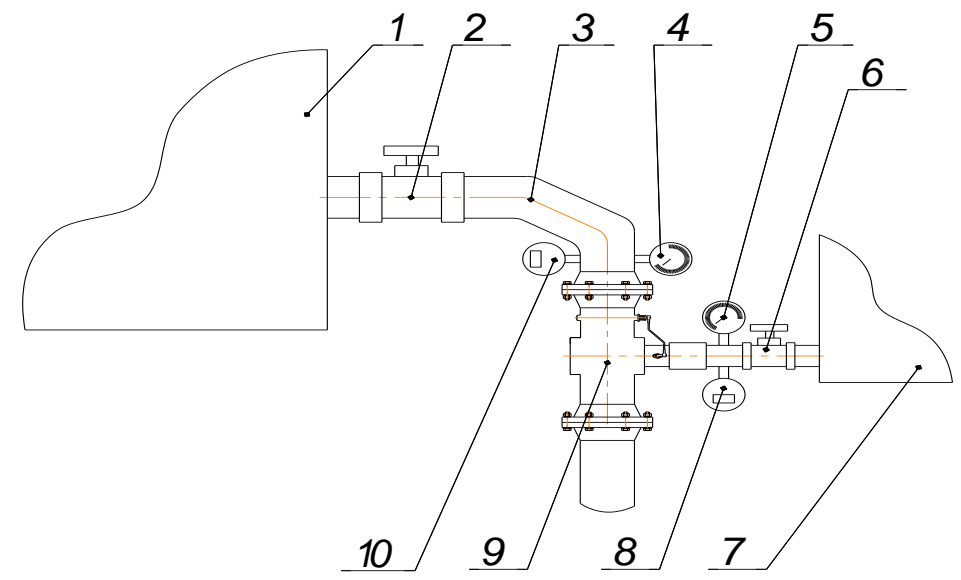

Fig. 1. Test unit 
The experimental plant consists of a large container 1 for squeezed juice, a smaller container 7 for organic acid solution, a batcher mixer 9 and a pipe 3 connecting both containers, on which the batcher mixer itself is placed. Speed sensor 10 is to determine the outflow velocity of squeezed juice, and the velocity sensor 8 is to determine the outflow velocity of organic acid solution. Pressure of squeezed juice flow is measured by the pressure gauge 4 and pressure of organic acid solution in inlet branch of mixing element is measured by the pressure gauge 5. There is a tap 2 to stop the supply of squeezed juice and there is a tap 6 to stop the supply of organic acid solution.

The test unit in a form of the liquid batcher mixer is designed in such a way that it allows studying various parameters of the machine.

The use of the test unit made it possible to obtain the dependence of the parameters of the technological process of coagulation of vegetable protein from beet pulp on the concentration of a solution of organic acids (Fig. 2-3).

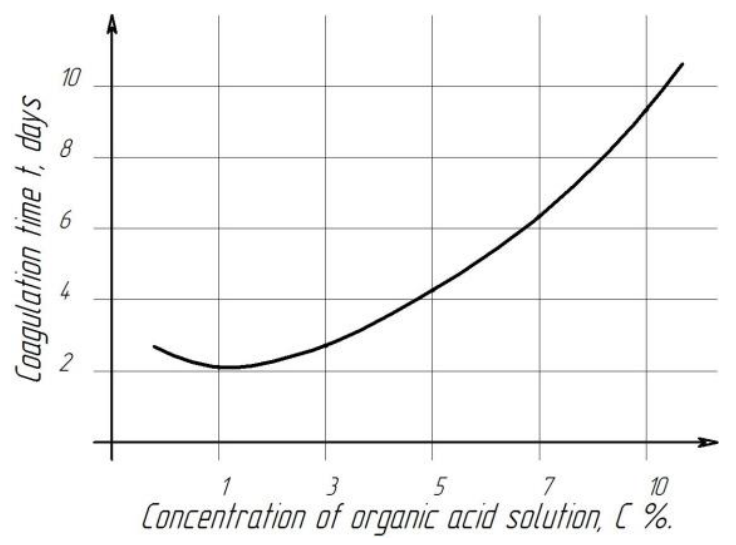

Fig. 2. Dependence of coagulation time on concentration of organic acid solution

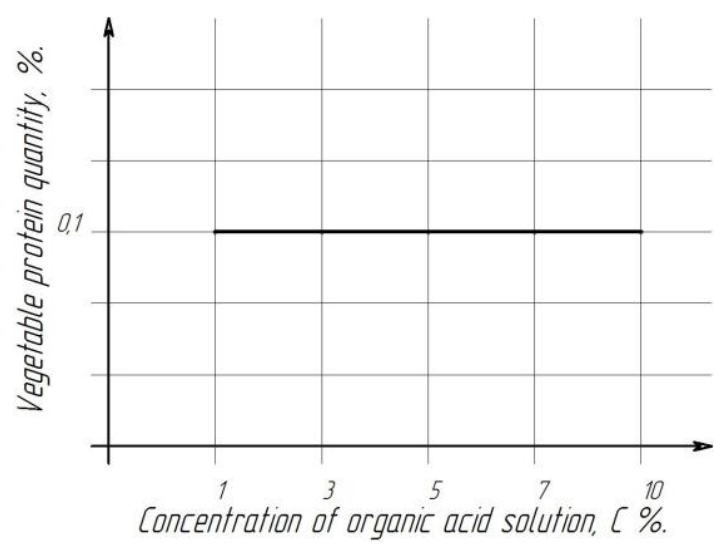

Fig. 3. Dependence of vegetable protein quantity on concentration of organic acid solution

Analyses of the dependences represented in Fig. 2 and Fig. 3 show that the coagulation time (precipitation of protein) increases with an increase in the concentration of the organic acid solution, the optimal concentration of the organic acid solution is $1 \%$, the increase in concentration leads to preservation of juice. At the same time, the concentration of organic acid solution does not affect the amount of the obtained vegetable protein, it is always constant and makes up $0.1 \%$ of the total amount of juice. The optimization criteria are selected as two indicators: the uniformity of the distribution of the solution of organic acids in the juice (coefficient of variation) $v$ and the uniformity of the application of the solution of organic acids in the juice $\delta$. The factors presented in Table 1 mainly influence on these indicators. The intervals and levels of variation of independent variables are also shown in Table 1.

Factors affecting on indicators of batcher mixer

Table 1

\begin{tabular}{|c|l|c|c|}
\hline \multirow{2}{*}{ Identifier } & \multicolumn{1}{|c|}{ Factors } & \multicolumn{2}{|c|}{ Levels } \\
\cline { 3 - 4 } & & $-\mathbf{I}$ & $+\mathbf{I}$ \\
\hline$X_{1}$ & Pipe diameter of main juice flow, $\mathrm{mm}$ & 90 & 100 \\
\hline$X_{2}$ & Pipe diameter for supply of organic acid solution, mm & 10 & 20 \\
\hline$X_{3}$ & Number of outlet branches of mixing element, pcs. & 12 & 20 \\
\hline$X_{4}$ & $\begin{array}{l}\text { Diameter of outlet holes for organic acid solution flow from mixing element, } \\
\text { mm }\end{array}$ & 0.5 & 1.5 \\
\hline$X_{5}$ & Juice flow pressure, $\mathrm{kPa}$ & 0.1 & 0.3 \\
\hline$X_{6}$ & Pressure of organic acid solution in mixing element inlet branch, $\mathrm{kPa}$ & 0.05 & 0.2 \\
\hline$X_{7}$ & Juice outflow velocity, $\mathrm{m} \cdot \mathrm{s}^{-1}$ & 0.3 & 0.55 \\
\hline$X_{8}$ & Outflow velocity of organic acid solution, $\mathrm{m} \cdot \mathrm{s}^{-1}$ & 0.2 & 0.4 \\
\hline
\end{tabular}

A planning matrix is defined to plan a full factor experiment. All possible combinations of factor values are presented in the matrix. The experiment planning matrix is based on experiment $2^{5}$, and the 
effects from the sixth, seventh and eighth factors are mixed with the effects of interaction. Each experience planned by the matrix corresponded to its own design of a batcher mixer.

Therefore, the working elements of the batcher mixer were changed at each test. The remaining parameters were set according to the matrix, while the mixture remained constant. Each test was carried out in triplicate.

As a result of such planning, a small portion of the response surface is described by an incomplete quadratic equation of the form:

$$
\begin{aligned}
& y=x_{0}+a \cdot x_{1}+b \cdot x_{2}+c \cdot x_{3}+d \cdot x_{4}+e \cdot x_{5}+f \cdot x_{6}+g \cdot x_{7}+h \cdot x_{8}+i \cdot x_{1} x_{2}+j \cdot x_{1} x_{3}+ \\
& +k \cdot x_{1} x_{4}+l \cdot x_{1} x_{5}+m \cdot x_{2} x_{3}+n \cdot x_{2} x_{4}+o \cdot x_{2} x_{5}+p \cdot x_{3} x_{4}+q \cdot x_{3} x_{5}+r \cdot x_{4} x_{5}+s \cdot x_{1} x_{2} x_{3}+ \\
& +t \cdot x_{1} x_{2} x_{4}+u \cdot x_{1} x_{2} x_{5}+v \cdot x_{1} x_{3} x_{4}+w \cdot x_{1} x_{3} x_{5}+x \cdot x_{1} x_{4} x_{5}+y \cdot x_{2} x_{3} x_{4}+z \cdot x_{2} x_{3} x_{5}+ \\
& +a_{1} \cdot x_{2} x_{4} x_{5}+b_{1} \cdot x_{3} x_{4} x_{5}+c_{1} \cdot x_{1} x_{2} x_{3} x_{4}+d_{1} \cdot x_{2} x_{3} x_{4} x_{5}+e_{1} \cdot x_{1} x_{2} x_{3} x_{4} x_{5} .
\end{aligned}
$$

All coefficients are determined and evaluated independently of each other. The magnitude of the regression coefficients indicates the significance of a factor. If a factor turns out to be insignificant, it can be excluded from the equation, while all other factors do not need to be recalculated.

The values of the regression coefficients of equation were obtained using the program "Eureka: The Solver, Version 1.0" on PC.

The calculation of regression coefficients gave the following equations:

$$
\begin{aligned}
& v=1.08-0.28 \cdot x_{1}+0.71 \cdot x_{2}+0.80 \cdot x_{3}+0.99 \cdot x_{4}+0.97 \cdot x_{5}+1.08 \cdot x_{6}+0.97 \cdot x_{7}+ \\
& 1.07 \cdot x_{8}+0.98 \cdot x_{1} x_{4}+1.02 \cdot x_{1} x_{5}+0.76 \cdot x_{2} x_{3}+1.05 \cdot x_{2} x_{4}+1.01 \cdot x_{2} x_{5}+0.95 \cdot x_{3} x_{4}+ \\
& +0.92 \cdot x_{3} x_{5}+1.09 \cdot x_{4} x_{5}+0.91 \cdot x_{1} x_{2} x_{4}+1.05 \cdot x_{1} x_{2} x_{5}-0.31 \cdot x_{1} x_{3} x_{4}+0.74 \cdot x_{1} x_{3} x_{5}+ \\
& +0.91 \cdot x_{1} x_{4} x_{5}+0.76 \cdot x_{2} x_{3} x_{4}+0.86 \cdot x_{2} x_{3} x_{5}+1.09 \cdot x_{2} x_{4} x_{5}-0.94 \cdot x_{3} x_{4} x_{5}+ \\
& +0.99 \cdot x_{2} x_{3} x_{4} x_{5}+0.70 \cdot x_{1} x_{2} x_{3} x_{4} x_{5} ; \\
& \delta=1.09+0.73 \cdot x_{1}+0.87 \cdot x_{2}+0.97 \cdot x_{3}+1.00 \cdot x_{4}+0.97 \cdot x_{5}+1.08 \cdot x_{6}+ \\
& 0.97 \cdot x_{7}+1.07 \cdot x_{8}+0.85 \cdot x_{1} x_{4}+1.00 \cdot x_{1} x_{5}+0.82 \cdot x_{2} x_{3}+0.96 \cdot x_{2} x_{4}+1.08 \cdot x_{2} x_{5}+ \\
& +1.08 \cdot x_{3} x_{4}+0.92 \cdot x_{3} x_{5}+0.96 \cdot x_{4} x_{5}+0.95 \cdot x_{1} x_{2} x_{4}+0.91 \cdot x_{1} x_{2} x_{5}-0.25 \cdot x_{1} x_{3} x_{4}+ \\
& +0.79 \cdot x_{1} x_{3} x_{5}+0.98 \cdot x_{1} x_{4} x_{5}+0.72 \cdot x_{2} x_{3} x_{4}+0.88 \cdot x_{2} x_{3} x_{5}+0.91 \cdot x_{2} x_{4} x_{5}- \\
& -1.04 \cdot x_{3} x_{4} x_{5}+0.91 \cdot x_{2} x_{3} x_{4} x_{5}+0.76 \cdot x_{1} x_{2} x_{3} x_{4} x_{5} .
\end{aligned}
$$

As a result of the obtained equations, it can be concluded that the uniformity of the distribution of the solution of organic acids into the juice $v$ is significantly influenced by: the pressure of the solution of organic acids in the inlet branch of the mixing element $X_{6}$, the outflow velocity of the solution of organic acids $X_{8}$, and the interaction of the factors; $X_{1} X_{5} ; X_{2} X_{4} ; X_{2} X_{5} ; X_{4} X_{5} ; X_{1} X_{2} X_{5} ; X_{2} X_{4} X_{5}$.

The uniformity of the application of the solution of organic acids in the juice $\delta$ is significantly influenced by: the diameter of the outlet holes for the solution of organic acids to flow out of the mixing element $X_{4}$, the pressure of the solution of organic acids in the inlet branch of the mixing element $X_{6}$, the outflow velocity of the solution of organic acids $X_{8}$ and the interaction of the factors $X_{2} X_{5} ; X_{3} X_{4}$; $X_{3} X_{4} X_{5}$. Visualization of the effect of various design parameters of the batcher mixer on the uniformity of application and distribution of the solution of organic acids in the juice is provided using threedimensional sections of the response surface in the center of the experiment (Fig. 4-5).
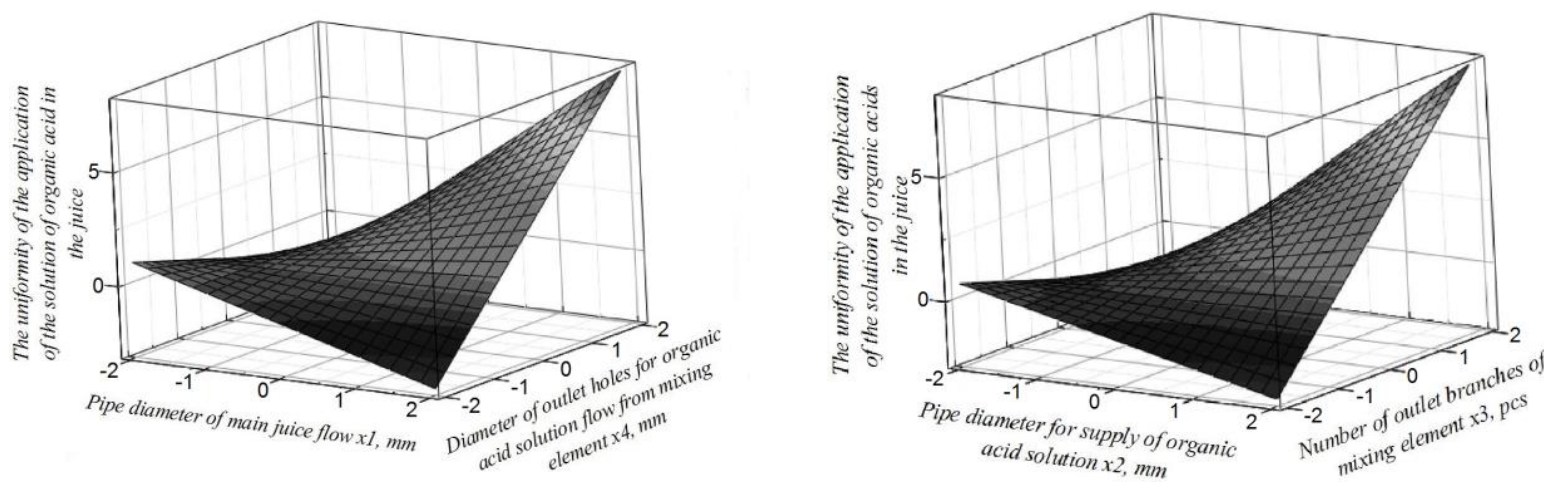

Fig. 4. Dependencies of uniformity of application of solution of organic acids into juice on parameters of batcher mixer 

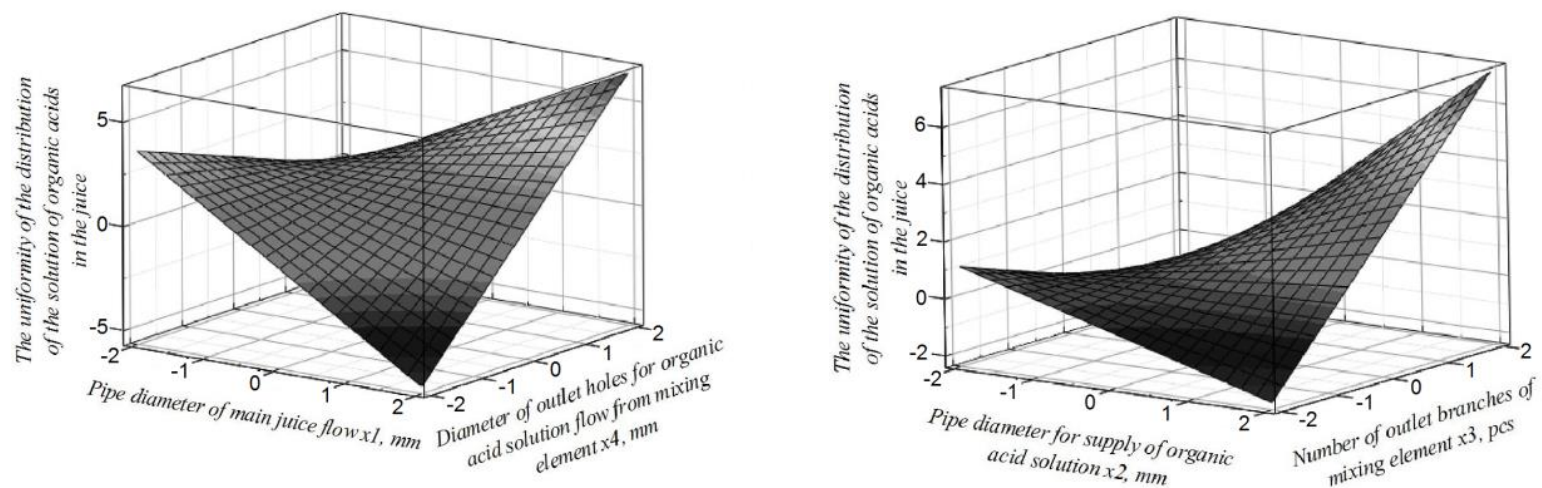

Fig. 5. Dependencies of uniformity of distribution of solution of organic acids in juice on parameters of batcher mixer

Analyzing the presented dependencies shows that an increase in the main design-mode parameters decreases the coefficient of variation. Therefore, the uniformity of application and distribution of the solution of organic acids in the juice increases. Table 2 shows the optimal design-mode parameters of the liquid batcher mixer.

Table 2

Optimal values of design-mode parameters of liquid batcher mixer

\begin{tabular}{|l|c|c|}
\hline \multicolumn{1}{|c|}{ Factors } & $\begin{array}{c}\text { Factor } \\
\text { identifier }\end{array}$ & Factor score \\
\hline Pipe diameter of main juice flow, mm & $X_{1}$ & $95-97$ \\
\hline Pipe diameter for supply of organic acid solution, mm & $X_{2}$ & $10-11$ \\
\hline Number of outlet branches of mixing element, pcs & $X_{3}$ & $12-13$ \\
\hline $\begin{array}{l}\text { Diameter of outlet holes for organic acid solution flow from mixing } \\
\text { element, mm }\end{array}$ & $X_{4}$ & $0.9-1.0$ \\
\hline Juice flow pressure, $\mathrm{kPa}$ & $X_{5}$ & $0.24-0.26$ \\
\hline Pressure of organic acid solution in mixing element inlet branch, $\mathrm{kPa}$ & $X_{6}$ & $0.14-0.16$ \\
\hline Juice outflow velocity, $\mathrm{m} \cdot \mathrm{s}^{-1}$ & $X_{7}$ & $0.52-0.54$ \\
\hline Outflow velocity of organic acid solution, $\mathrm{m} \cdot \mathrm{s}^{-1}$ & $X_{8}$ & $0.35-0.37$ \\
\hline
\end{tabular}

As a result of the experimental studies, it was established that the liquid batcher mixer is operable and effective in all modes of operation. The design of the unit allows quick reconfiguration of the designmode parameters of the liquid batcher mixer.

\section{Conclusions}

1. The uniform distribution of the solution of organic acids in the juice is more influenced by the pressure of the solution of organic acids in the inlet branch of the mixing element and the outflow velocity of the solution of organic acids.

2. The uniformity of application of organic acid solution into juice is more influenced by the diameter of the outlet holes for flow of organic acid solution from the mixing element, pressure of organic acid solution in the inlet branch of the mixing element and outflow velocity organic acid solution.

3. Theoretical and experimental data of the working process of the liquid batcher mixer made it possible to determine its optimal values of design-mode parameters: the diameter of the pipe of the main stream of juice is $95 . . .97 \mathrm{~mm}$; diameter of the pipe for supply of solution of organic acids $9 . .11 \mathrm{~mm}$; number of outlet branches of the mixing element $-11 \ldots 13 \mathrm{pcs}$; diameter of the outlet holes for organic acid solution flow from the mixing element $-0.9 \ldots 1.0 \mathrm{~mm}$; juice flow pressure $0.24 \ldots 0.26 \mathrm{MPa}$; pressure of organic acid solution in the inlet branch of the mixing element $0.14 \ldots 0.16 \mathrm{MPa}$; juice outflow velocity $-0.52 \ldots 0.54 \mathrm{~m} \cdot \mathrm{s}^{-1}$ and organic acid solution outflow velocity $-0.35 \ldots 0.37 \mathrm{~m} \cdot \mathrm{s}^{-1}$. 


\section{References}

[1] Zhilyakov D. I. et al. Trends and prospects for the development of horticulture and vegetable growing in the region. IOP Conf. Ser.: Earth Environ, Sci. 548, 2020, pp. 082039, DOI: 10.1088/1755-1315/548/8/082039.

[2] Zhou Qing Yuan, et al. Agricultural Modernization Index System and Evaluation Method Research. Key Engineering Materials, vol. 439-440, 2010, pp. 842-847,

DOI: $10.4028 /$ www.scientific.net/kem.439-440.842.

[3] Vodolazskaya N. Types and ways of modernization in a context of the international experience. Virtual Economics, vol.2, No 2(1), 2019, pp. 81-93, DOI: 10.34021/ve.2019.02.01(5).

[4] Zhao Hong Wei, et al. Comprehensive Evaluation System Research on Agricultural Modernization Based on Principal Component of BP Network. Applied Mechanics and Materials, vol. 472, 2014, pp. 948-952. DOI: 10.4028/www.scientific.net/amm.472.948.

[5] Vodolazskaya N., Sharaya O. Modifying of the Surface of Products from Cast Iron as the Element of Production Modernization. Solid State Phenomena, vol. 299, 2020, pp. 588-593, DOI: 10.4028/www.scientific.net/SSP.299.588.

[6] Рыбалкин Н.А., Лебедев А.Т., Павлюк Р.В. Improvement of feed mixing process in blade mixer (Совершенствование процесса смешивания кормов в лопастном смесителе). Innovation in the agro-industrial complex: problems and prospects, 2020, № 3 (27), pp. 78-84. (In Russian).

[7] Kapinos R.V., Chovgan N.I., Akupiyan O.S., Kravchenko D.P. Economics, organization and management of environmental engineering in farms and rural individual entrepreneurs of environmental orientation. Journal of Physics: Conf. Series, 1679, 2020, pp. 052-075, DOI: 10.1088/1742-6596/1679/5/052075.

[8] Haraszi R., Gras P.W., Tömösközi S., Salgó A., Békés F. Application of a micro Z-arm mixer to characterize mixing properties and water absorption of wheat flour. Cereal Chemistry, vol. 81, Iss. 5, 2004, pp. 555-560.

[9] Leijdekkers A.G.M., Bink J.P.M., Geutjes S., Schols H.A., Gruppen H. Enzymatic saccharification of sugar beet pulp for the production of galacturonic acid and arabinose. Bioresource Technology, № 128, 2013, pp. 518-525.

[10] .Булавин С.А., Казаков К.В., Колесников А.С. Waste energy-saving beet pulp processing technology (Безотходная энергосберегающая технология переработки свекловичного жома). Sugar, № 3, 2011, pp. 36-38. (In Russian).

[11] Fan Zhi Min, et al. Study on the Applied Research of a Different-Speed Mixer. Advanced Materials Research, vol. 221, 2011, pp. 629-634, DOI: 10.4028/www.scientific.net/amr.221.629.

[12] Peter Savinyh, Alexey Aleshkin, Nikolai Turbanov, Semjons Ivanovs Investigation of impact of technological and structural parameters upon energy indicators of work of mixer. Engineering for rural development, 20-22.05.2020, Jelgava, Latvia, pp. 1338-1448.

[13] Мачкарин А.В., Рыжков А.В. Теоретические исследования вибросмешивания сыпучих кормов (Theoretical studies of vibration mixing of bulk feed). Innovations in agrarian and industrial complex: problems and prospects, No 3 (23), 2019, pp. 43-55. (In Russian).

[14] Gong Bing, Xiao Jing Zhu Experimental Study of Turbulence Properties in a SMX Mixer. Advanced Materials Research, vol. 516-517, 2012, pp. 900-905,

DOI: 10.4028/www.scientific.net/amr.516-517.900.

[15] Kolesnikov A., Pastukhov A., Vodolazskaya N., Minasyan A. Research in parameters of working process of interfusing in batcher mixer. Engineering for rural development, Jelgava: Latvia University of Life Sciences and Technologies, vol. 18, 2019, pp. 487-492, DOI: 10.22616/ERDev2019.18.N033.

[16] Slobodyuk A., Strebkov S., Bondarev A. Modernization of structural design of op-2000 sprayer using APM WinMachine CAE system. Engineering for Rural Development. 20-22.05.2020, Jelgava, Latvia, pp. 94-101, DOI: 10.22616/ERDev2020.19.TF022.

[17] Zhang Z. Optimal Analysis of Farm Agricultural Machinery Equipment Based on Mathematical Modelling. INMATEH - Agricultural Engineering, vol. 62, Iss. 3, 2020, pp. 333-340. 